\title{
Development of a Five-Day Basic Microsurgery Simulation Training Course: A Cost Analysis
}

\author{
Masha Singh ${ }^{1}$, Natalia Ziolkowski ${ }^{2}$, Savitha Ramachandran ${ }^{3}$, Simon R Myers ${ }^{1}$, \\ Ali Mahmoud Ghanem ${ }^{1}$ \\ ${ }^{I}$ Academic Plastic Surgery Group, Centre for Cutaneous Research, Barts and the London School of Medicine and Dentistry, Blizard Institute, \\ London, UK; ${ }^{2}$ Department of General, Vascular and Oncologic Surgery, Medical University of Warsaw, Warsaw, Poland; ${ }^{3}$ Department of \\ Plastic Surgery, KK Women's and Children's Hospital, Singapore
}

The widespread use of microsurgery in numerous surgical fields has increased the need for basic microsurgical training outside of the operating room. The traditional start of microsurgical training has been in undertaking a 5-day basic microsurgery course. In an era characterised by financial constraints in academic and healthcare institutions as well as increasing emphasis on patient safety, there has been a shift in microsurgery training to simulation environments. This paper reviews the stepwise framework of microsurgical skill acquisition providing a cost analysis of basic microsurgery courses in order to aid planning and dissemination of microsurgical training worldwide.

Keywords Cost and cost analysis / Education / Microsurgery
Correspondence:

Ali Mahmoud Ghanem

Academic Plastic Surgery Group, Centre for Cutaneous Research, Barts and the London School of Medicine and Dentistry, Blizard Institute, 4 New Ark Street, London E1 2AT, London, UK Tel: +44-20-7882-7173

Fax: +44-20-7882-7171

E-mail:a.ghanem@qmul.ac.uk

No potential conflict of interest relevant to this article was reported.

Received: 23 Jan 2013 • Revised: 15 Mar 2013 • Accepted: 26 Mar 2013

pISSN: 2234-6163• elSSN: 2234-6171 • http://dx.doi.org/10.5999/aps.2014.41.3.213• Arch Plast Surg 2014;41:213-217

\section{INTRODUCTION}

Since the introduction of microsurgery in the early 1900s, the use of microscopes in the operating theatre has been adopted by many specialties, such as plastic surgery, ophthalmology, urology and maxillo-facial surgery, amongst others [1]. Microsurgery is considered to be one of the most challenging fields of surgery, based on the degree of dexterity and manual skill required by the operator [2]. As such, there can be a significant learning curve in acquisition of microsurgical skill and with the risks to patients in terms of morbidity and even mortality associated with a failed microsurgical anastomosis, coupled with a reduction in training time, a need for training outside of the operating theatre has arisen [3].

Currently, around the world, there are a number of microsurgery courses available to trainees, advertised as basic and advanced courses. The basic courses are aimed at trainees who may have had no previous microsurgical experience, whereas advanced courses build upon pre-existing microsurgical techniques. Most use living rats, which are an excellent model to teach a myriad of techniques and skills needed to acquire competence in microvascular anastomosis. However, setting up a comprehensive living rat model training course in microsurgery is often associated with significant costs, with fees for such courses running to well over $\$ 2,000$. With a shift towards simulation, the aim of this paper is to review the structure of available basic microsurgery courses and perform a cost analysis of creating a basic microsurgery training course based on non-living models.

\section{COURSE CONTENT}

Basic microsurgery courses are aimed at surgical trainees with 
little to no experience of microsurgery, although, can cater for those with more skill. Most modern courses are five days, ranging from 35 to 40 hours of content. Within this, the majority uses a 'step ladder' approach to training, introducing basic techniques and then building upon these in subsequent sessions/days. Common microsurgery courses from around the world typically follow the same step-wise approach to training. For example, day 1 content typically covers an introduction to the operating microscope, microsurgical instruments and handling of fine suture (9-0 or 10-0) to perform simple interrupted stitches. This then progresses to end-to-end anastomoses of arteries, and veins. Following this, end-to-side anastomoses are performed and then inter-positional vein grafts. From this point, some courses go on to include a free groin flap, although, this will obviously be dependent on the candidate performing adequately up to then. Overall, most begin with candidates working on non-living models, then on to live rat models. Although the progression of complexity of model is essential, the use of live rat models raises certain issues. These include, the obvious ethical concerns of using live animals, as well as the associated costs, not just in procurement of the models and associated handling costs, but also, here in the UK, the fees for a Home Office licence to allow use of live animals [4]. Given these issues, there is an increasing drive towards use of non-living models, where possible, to allow skill development without these concerns. Work by Fanua et al. [5] also found that practice on non-living models significantly reduced the subsequent need for live animals and had associated reduced costs.

To allow comparison of non-living models with live models, it is useful to classify models by their training goal. Ilie et al. [6] organized microsurgical models into five main groups: 1) Basic manipulation, movement, and orientation in the microscopic field. 2) Knot placement/tying principles-apposition of edges, non-dominant hand usage, deformable volumes. 3) Threedimensional models/completing the anastomosis. 4) The real tissue experience.

The proposed fifth group covered the use of virtual reality trainers, the role, of which, is as yet unclear in microsurgical training. Using this framework, we aimed to conduct a cost analysis of different models available for each stage. Some models will have application at more than one stage, although, may be less effective than other available models. All prices listed are inclusive of local taxes and have been converted to US dollars based on current exchange rates and as such may be subject to change. The costs reviewed do not cover those of the premises to run the course, the workstations, operating microscopes, instruments or staff costs as these may vary greatly internationally.

\section{MICROSURGICAL TRAINING}

\section{Basic manipulation, movement, and orientation in the microscopicfield}

This stage is the most basic; the aim is to develop the fundamental skills of using microsurgical instruments under a magnified field. The minimum requirements would be an operating microscope, microsurgical instruments and suture. Models used to develop these basic skills include surgical gauze, in which a candidate must pass a suture above and below adjacent threads [7]. Other models include beads, allowing candidates to practice passing suture through fine apertures and delicate handling of materials and also an 'around the clock' model, consisting of sewing needles placed in a clock face pattern, with the eye of each needle at the numerical position of a clock face e.g., one o'clock, two o'clock etc. [8,9]. The candidate then tries to pass a suture through the needles in a sequential clockwise manner.

In terms of costs, the price of gauze can be reduced by using non-sterile material and buying in bulk. We were able to purchase 4 " $\times 4$ " non-sterile, 12 ply gauze for around 4 cents per sheet. Although, it should be noted that each sheet could be divided and used for two or more candidates. There are a large variety of beads available, however we favour those with a 1.5 $\mathrm{mm}$ drill hole to help mimic the size of vessels candidates may encounter. We managed to source wooden beads for $\$ 2.4$ for 100 , which, if bought in bulk, has no shipping cost. Sewing needles are available with a wide range of sizes, with the size of the eye of the needle related to the needle diameter, typically size 10 or 12 would be appropriate. Table 1 summarises the main costs of the models suggested.

\section{Knot placement/tying principles-apposition of edges, non-dominant hand usage, deformable volumes}

This stage of training assumes fundamental skills in manipulation of instruments in a microsurgical field. IIt involves the practice of basic suturing on non-tubular structures, the main models available are latex gloves mounted over a platform to spread out the material and use of a specially made practice card, of similar properties [10]. Both allow straight-line incisions to be made and suturing to be attempted. Although nonsterile latex gloves are easily available, they require mounting and preparation, newer practice cards are available which come ready made. Sharpoint, for example, produce a mounted latex membrane with coloured background, called PracticePak. Table 2 compares the costs of these models.

Three-dimensional models/completing the anastomosis When considering the use of three-dimensional (3D) models 
Table 1. Summary of costs for models to aid in basic microsurgical manipulation tasks

\begin{tabular}{|lcc|}
\hline Model & $\begin{array}{c}\text { Cost including } \\
\text { shipping (US Dollar) }\end{array}$ & $\begin{array}{c}\text { Cost per item } \\
\text { (US Dollar) }\end{array}$ \\
\hline $\begin{array}{l}\text { Non-sterile gauze swabs } \\
(2,000 \text { items set) }\end{array}$ & 83.21 & 0.04 \\
$\begin{array}{l}\text { Wooden beads) }(100 \text { items set) } \\
\text { Sewing needles }\end{array}$ (4 items set) & 2.42 & 0.02 \\
& 3.53 & 0.88
\end{tabular}

a)Models are useful for the development of basic microsurgical instrument and object manipulation. Gauze may be used to practice weaving of microsurgical suture between threads; ${ }^{b}$ Models are useful for manipulating and controlling the needle when passing it through the centre of wooden beads or sewing needle eyes.

Table 2. Summary of costs for models to aid in microsurgical knot placement and tying

\begin{tabular}{|lcc|}
\hline Model & $\begin{array}{c}\text { Cost including } \\
\text { shipping (US Dollar) }\end{array}$ & $\begin{array}{c}\text { Cost per item } \\
\text { (US Dollar) }\end{array}$ \\
\hline Latex gloves) $^{\text {a) }}(2,000$ item pack) & 137.43 & 0.07 \\
PracticePak & 38.71 & 38.71 \\
\hline $\begin{array}{l}\text { a) Models are useful for the development of microsurgical knot placement and tying. } \\
\text { Latex gloves may be stretched onto a frame or a commercially pre made latex } \\
\text { sheet may be used to practice suturing incisions in the latex sheet. }\end{array}$ \\
\hline
\end{tabular}

for anastomosis, most microsurgical courses use live rat models for arterial, venous and nerve repair procedures. However, due to the reasons previously mentioned, such as ethical considerations and hygiene issues, there is a drive towards more realistic non-living synthetic models supported by the development of ever more sophisticated materials. The most basic models available include micro-silicone tubes, such as those used for electrical wire insulation and Gore-Tex (polytetrafluoroethylene) tubes, which, although not actively used in microsurgery, have found use in vascular by-pass surgery $[11,12]$. Gore-Tex tubes have the advantage that they are believed to behave more like biological vessels than silicone tubes. We also suggest the novel use of intra-venous cannula tubing (Polyurethane) as a useful anastomotic model. Any needle 17 gauge or larger will have a surrounding sheath of at least $1.5 \mathrm{~mm}$ internal diameter and so should be suitable, it merely requires removal of the needle and securing the model to a base, facilitated by the wings present on most modern cannulae.

Newer models aim to mimic the handling characteristics of biological tissues more closely, such as synthetic arteries, veins and nerves. Although there are many suppliers, our personal experience has been from SynDaver, based in the United States. They are able to supply vessels comparable to human digital vessels in size and in fascial sleeves to aid mounting onto appropriate models. More sophisticated models include the PracticeRat, which again can mimic artery, vein and nerve and aims to recre-
Table 3. Summary of costs for models to aid in microsurgical anastomosis/nerve repair

\begin{tabular}{|c|c|c|}
\hline Model & $\begin{array}{c}\text { Cost including } \\
\text { shipping (US Dollar) }\end{array}$ & $\begin{array}{l}\text { Cost per item } \\
\text { (US Dollar) }\end{array}$ \\
\hline $\begin{array}{l}\text { Silicone tubes }{ }^{\mathrm{a})}(5 \mathrm{~m} \text { of } 2 \mathrm{~mm} \\
\text { outer diameter tubing) }\end{array}$ & 32.32 & 0.07 per $\mathrm{cm}$ \\
\hline $\begin{array}{l}\text { Cannula tubinga) (box of } 5017 \mathrm{G} \\
\text { cannulae) }\end{array}$ & 105.49 & 2.11 \\
\hline $\begin{array}{l}\text { SynDaver synthetic artery with } \\
\text { fascia) }(10 \mathrm{~cm} \text { item })\end{array}$ & $\begin{array}{l}\text { Available in packs of } \\
\text { variable quantities }\end{array}$ & 10 \\
\hline $\begin{array}{l}\text { SynDaver synthetic vein with } \\
\text { fasciaa) }^{\text {(10 }} \mathrm{cm} \text { item) }\end{array}$ & $\begin{array}{l}\text { Available in packs of } \\
\text { variable quantities }\end{array}$ & 10 per vessel \\
\hline $\begin{array}{l}\text { SynDaver synthetic nerve }{ }^{\mathrm{a}} \\
(10 \mathrm{~cm} \text { item) }\end{array}$ & $\begin{array}{l}\text { Available in packs of } \\
\text { variable quantities }\end{array}$ & 10 \\
\hline $\begin{array}{l}\text { PracticeRat-(model includes } \\
\text { artery, vein with adventitia and } \\
\text { sciatic nerve) }\end{array}$ & 276.79 & 276.79 per \\
\hline $\begin{array}{l}\text { PVC Rat } \\
\text { (model includes artery and vein) }{ }^{2)}\end{array}$ & 449.61 & 449.61 \\
\hline \multicolumn{3}{|c|}{$\begin{array}{l}\text { a) Models useful for the development of microvascular anastomosis and nerve } \\
\text { repair. All models represent tubing of comparable diameters to living rat femoral } \\
\text { vessels. }\end{array}$} \\
\hline
\end{tabular}

ate adventitia. The most complex model currently available is the PVC Rat, which although aimed more at research scientists, creates realistic anastomotic experiences in an actual rat model. It also comes with software, which when used in an attached computer, simulates aspects of live animal care, with measures such as temperature, heart rate and respiratory rate displayed on screen. Table 3 summarises the cost for different anastomotic models.

\section{The biological tissue experience}

Biological tissue models can be further divided into non-living and vital examples. The most convenient in terms of purchasing, preparation and cost are chicken vessels. Fresh chicken wings and legs are easily available at local butchers or supermarkets, although prices can vary. Both have been previously published as useful models for microsurgical training [13-16]. Fresh chicken wings allow arterial anastomosis of the brachial artery, which is comparable in size to a human digital vessel. Fresh chicken legs allow anastomosis of the femoral artery, vein and sciatic nerve.

A commonly used non-living model is cryopreserved rat aorta, which we were able to source locally for $\$ 32.36$ per 3 to 5 $\mathrm{cm}$ segment [17]. This cost was further reduced to $\$ 8.07$ per 3 to $5 \mathrm{~cm}$ segment if the rats were sacrificed following their use in experimental research. We found this model to be particularly useful in the early stages of training, due to an average vessel diameter of 3 to $4 \mathrm{~mm}$. We were also able to obtain freshly killed rat femoral vessels and sciatic nerves. The prices for these can be variable and are very dependent on the number of rats required. The prices include acquisition of the rats and maintenance costs, as well as all handling and shipping costs. The costs for live rat 
Table 4. Summary of costs for biological tissue microsurgical models

\begin{tabular}{|c|c|c|}
\hline Model & Cost including shipping (US Dollar) & Cost per item (US Dollar) \\
\hline Chicken wings ${ }^{\text {a) }}$ (set of 6 items) & 3.65 & 0.61 \\
\hline Chicken legs ${ }^{\text {a) }}$ (set of 6 items) & 5.9 per & 0.97 \\
\hline $\begin{array}{l}\text { Cryopreserved rat aorta } \\
\text { (harvested from rats used in live animal courses and or research) }\end{array}$ & 6.26 & 6.26 \\
\hline Freshly killed rat (model contains 2 femoral arteries, veins or sciatic nerves)a) & 30 & 30 \\
\hline Live rat mode $\left.\right|^{b)}$ & 30 & 30 \\
\hline
\end{tabular}

models were similar, however, the course tutor will require a Home Office licence to allow work with live animals. Each candidate will also require a Home Office personal licence for work with live rats over the duration of the course, costs are summarized in Table 4.

\section{DISCUSSION}

Although a variety of microsurgical training courses are currently available, most follow a similar step-wise progression of training models. Day one, typically, involves an introduction to the operating microscope and practice of simple suturing. From this point, simple manipulation tasks are performed on gauze, beads or sewing needles. We found the costs per candidate ranged from 4 cents to $\$ 10.6$ for these models. However, many can be reused and the costs may represent only initial outlays.

In practicing knot placement and tying procedures, a latex practice card provides an ideal model on which to operate. It allows candidates to become proficient at microsurgical suturing on a stable base and represents an integral step before attempting a microvascular anastomosis. It can be easily fashioned by using a latex glove secured firmly, or the latest commercially available versions, such as PracticePak which come pre-made. Prices vary from 7 cents per glove to $\$ 38.71$ for a branded model.

There are a large variety of non-living synthetic models available on which to perform anastomoses, Table 3 summarises the costs involved for those most commonly used. Silicone tubes, Gore-Tex tubes and cannula tubing represent the simplest models, with no adventitia or surrounding tissue. The advantage of such models is that candidates can practice the basic suturing techniques learning how to optimize suture placement required for a successful anastomosis in isolation from tissue dissection, bleeding and other factors. The disadvantage of such models, however, is that the materials used often lack realistic tissue handling properties, with no equivalent to adventitia. More realistic examples include synthetic vessels, such as those manufactured by SynDaver. They produce synthetic arteries, veins and nerves, comparable in size to human digital vessels. They also claim to have near real vessel handling characteristics and include a surrounding adventitia, allowing practice of vessel preparation. The cost of these synthetic neurovascular models, although may be considered expensive, still compares favourably with living models. The most complex non-biological models included the PracticeRat and PVC Rat. The PracticeRat model contains lengths of synthetic artery, vein and nerve of $1 \mathrm{~mm}$ diameter. The vessels are purported to handle like biological vessels and also come in a surrounding adventitial layer. The model comes in a base, resembling a petri dish, but allows easy vessel or nerve mounting and also allows testing for anastomotic leaks via artificial blood (supplied separately) passed through attached mounting needles. The costs of the model initially may be high (\$276.79), but following this, costs are for replacement vessels/nerves only. The PVC Rat model may be the most expensive, but also simulates aspects of live animal care, via a supplied software program. The PVC Rat consists of a plastic model of a prosected rat, with synthetic arteries, veins and viscera. In total, it allows simulation of up to 25 different procedures, although most of these are not anastomotic. Again, as with the PracticeRat, after purchasing the model, only replacement vessels are required.

Most microsurgery courses worldwide make use of live rat models for microsurgical training, however, there are now many biological non-living alternatives. The most easily available models were fresh chicken wing and leg, which allowed anastomotic practice of arterial, venous and nerve repair, similar to the diameters of human digital neurovascular structures. The costs of these varied from 61 cents to 97 cents per model, the dissection required for vessel preparation is minimal and well described in the literature [13-16]. Cryopreserved rat aortae were also found be very useful, due in part to the larger diameter of the vessels, at around 3 to $4 \mathrm{~mm}[17]$. We, therefore suggest these may be of use in the early part of progression to biological tissues.

We were, also, able to obtain freshly sacrificed rat femoral vessels and sciatic nerves. Although these vessels would make ideal anastomotic models, vessel diameters were often less than 1 
$\mathrm{mm}$ and therefore may not be suitable for novices. The cost per rat was roughly $\$ 40.33$, but varied by number ordered. A single rat would therefore be able to provide 2 sets of femoral arteries, veins and sciatic nerve models and so cost $\$ 20.16$ per candidate. Other anatomical sites such as the rat aorta, jugular veins and carotid arteries may also be used from the same rat. Nevertheless, the use of sacrificed rats for training in microsurgery is subject to the same ethical considerations as a living rat model, however does not require Home Office licensing in the UK and so can substantially reduce costs. The live rat model incurred the same costs per rat, but in addition, is also subject to many further costs. These include not only Home Office licence fees, which are significant, but also the costs of anesthetic agents, feeding and maintenance facility.

We have found that there are now many cost effective alternatives to commonly used microsurgical training models at all stages of the learning curve. In some steps however, such as practicing knot placement and tying for example, the commercially available models (PracticePak) may still be significantly more expensive than alternatives. We believe the biggest savings to be made are with use of modern synthetic vessels and nerves and the use of non-living biological models, such as chicken vessels as alternatives to expensive live rat models. This not only results in obvious ethical and hygiene advantages, but from a pure cost point of view, there may be great savings to be made, for example, the cost of alive rat being around 30 dollars, compared with only 7 cents per $\mathrm{cm}$ of silicone tubing. By lowering the costs of microsurgical courses, it is hoped that they will therefore become more accessible. It should be noted, however, that non-living models are continuing to improve and attain greater levels of realism to the living model, but it may be argued that the lack of pulsatility, or a realistic adventitia may still limit their widespread use over living models.

We suggest that future work in this field is needed to focus on the comparison of learning outcomes achieved using these models as well as candidate experiences, rather than on a purely cost basis. This would provide a balanced overall view of currently available training models to enhance introduction and dissemination of microsurgical training worldwide.

\section{REFERENCES}

1. Tamai S. History of microsurgery: from the beginning until the end of the 1970s. Microsurgery 1993;14:6-13.
2. Erel E, Aiyenibe B, Butler PE. Microsurgery simulators in virtual reality: review. Microsurgery 2003;23:147-52.

3. Creswell B, Marron C, Harrison E, et al. Optimising working hours to provide quality in training and patient safety: a position statement by the Association of Surgeons in Training [Internet]. London: Association of Surgeons in Training; 2009 [cited 2012 Mar 19]. Available from: http:// www.asit.org/assets/documents/ASiT_EWTD_Position_ Statement.pdf.

4. Di Cataldo A, La Greca G, Rodolico M, et al. Experimental models in microsurgery. Microsurgery 1998;18:454-9.

5. Fanua SP, Kim J, Shaw Wilgis EF. Alternative model for teaching microsurgery. Microsurgery 2001;21:379-82.

6. Ilie VG, Ilie VI, Dobreanu C, et al. Training of microsurgical skills on nonliving models. Microsurgery 2008;28:571-7.

7. Demirseren ME, Tosa Y, Hosaka Y. Microsurgical training with surgical gauze: the first step. J Reconstr Microsurg 2003; 19:385-6.

8. Yenidunya MO, Tsukagoshi T, Hosaka Y. Microsurgical training with beads. J Reconstr Microsurg 1998;14:197-8.

9. Chan WY, Mishra A, Srinivasan J, et al. 360 degrees Microsurgical skills practice: a 'round-the-clock' training device. J Plast Reconstr Aesthet Surg 2008;61:1110-1.

10. Lahiri A, Lim AY, Qifen Z, et al. Microsurgical skills training: a new concept for simulation of vessel-wall suturing. Microsurgery 2005;25:21-4.

11. Peled IJ, Kaplan HY, Wexler MR. Microsilicone anastomoses. Ann Plast Surg 1983;10:331-2.

12. Korber KE, Kraemer BA. Use of small-caliber polytetrafluoroethylene (Gore-Tex) grafts in microsurgical training. Microsurgery 1989;10:113-5.

13. Hino A. Training in microvascular surgery using a chicken wing artery. Neurosurgery 2003;52:1495-7.

14. Krishnan KG, Dramm P, Schackert G. Simple and viable in vitro perfusion model for training microvascular anastomoses. Microsurgery 2004;24:335-8.

15. Marsh DJ, Norton SE, Mok J, et al. Microsurgical training: the chicken thigh model. Ann Plast Surg 2007;59:355-6.

16. Funatsu MK, Esteban D, Junior AH, et al. New training model for reconstructive microsurgery. Plast Reconstr Surg 2005; 116:692-4.

17. Lausada NR, Escudero E, Lamonega R, et al. Use of cryopreserved rat arteries for microsurgical training. Microsurgery $2005 ; 25: 500-1$. 